\title{
Study of Minimum Inhibitory Concentration Against a Local Field Isolates of Mycoplasma gallisepticum and Mycoplasma synoviae from Egyptian Broiler and Layer Chicken Flocks
}

\author{
Mustafa Bastamy ${ }^{1}$, Ismail Raheel ${ }^{2}$, Hany Ellakany $^{3}$ and Ahmed Orabi ${ }^{4 *}$ \\ ${ }^{1}$ Department of Poultry and Rabbits Disease, Faculty of Veterinary Medicine, Cairo University, Egypt \\ ${ }^{2}$ Department of Bacteriology, Mycology and Immunology, Faculty of Veterinary Medicine, Beni-Suief University, Egypt \\ ${ }^{3}$ Department of Poultry and Fish Diseases, Faculty of Veterinary Medicine, Damanhour University, Egypt \\ ${ }^{4}$ Department of Microbiology, Faculty of Veterinary Medicine, Cairo University, Egypt \\ *Corresponding author: drorabi2012@yahoo.com; orabivet@cu.edu.eg
}

Article History: $21-315 \quad$ Received: $12-$ May-21 Accepted: 18-Jul-21
ABS TRA C T
On a field level among poultry flocks, the efficacy of the most common antibiotics against Mycoplasma species was
decreased, Hence the traceability of the new updates about the minimum inhibitory concentration becomes very
important for veterinarians in fighting antibiotic resistant strains circulating among birds. In the current study the
minimum inhibitory concentrations (MICs) of the common anti-mycoplasma drugs as enrofloxacin, difloxacin
oxytetracycline, doxycycline, chlortetracycline, tylvalosin, erythromycin, tylosin, tilmicosin, spiramycin, tiamulin,
lincomycin, spectinomycin and dihydrostreptomycin against MG and MS isolates of broiler and layer chickens in
Egyptian farms and recorded in GenBank. The recovered results showed that till now the tylvalosin macrolides is the
most efficient drugs in the control of mycoplasmas as it has the lowest MICs value against local $M$. gallisepticum and
local $M$. synoviae as tylvalosin at dilution rate of $0.001-2 \mu \mathrm{g} / \mathrm{mL}$, showed the lowest values among the studied antibiotics
as MICs value were $0.001,0.005$ and $0.008 \mu \mathrm{g} / \mathrm{mL}$ against $\mathrm{MG}$ and $0.2,0.25$ and $0.5 \mu \mathrm{g} / \mathrm{mL}$ against MS strains.

Key words: Minimum inhibitory concentrations, M. gallisepticum (MG), M. synoviae (MS), Macrolides, Tylvalosin, Broiler chickens, Layers chickens.

\section{INTRODUCTION}

Avian Mycoplasma infection is extremely important to both the broilers and layers as it is worldwide disease possibly due to the growth of large flocks with in little geographically areas, increase stock density, under inadequately biosafety conditions at which Mycoplasma can affect grower poultry, generating important economic losses (OIE 2007; OIE 2008; Dufour et al. 2006). The most important pathogens associated with avian mycoplasmosis were M. gallisepticum and M. synoviae. M. gallisepticum producing, an infectious contagious avian respiratory disease with a large range of clinical lesions as increase of mortality $\%$, decrease eggs and meat production, decrease of fertility and hatchability $\%$, combined with high cost of treatment and control (Lockaby et al. 1998). M. synoviae is considered the main agent associated with avian infectious synovitis, which occurs in chickens and turkeys (Ramirez et al. 2006; Bosila et al. 2021). The prophylactic measures against avian mycoplasmosis are carried to obtain Mycoplasma free flocks. The prophylaxis is based on technological, hygienical and nutritional factors as; avoidance of stressors; discarding the other infectious diseases which may favors the evolution of mycoplasmosis; regular disinfections in hatcheries and farms; treatment of fertile eggs with antibiotics; treatment with antibiotics in the first days of life chicken against Mycoplasma as a preventive measure (Valks and Burch 2002). Economic losses caused by Mycoplasma's infection in chicken and turkey flocks, solely or in conjunction with other organisms are high and associated with an increase of condemnation rate, less final weight and decrease of egg production between 5 and $10 \%$, poor feed conversion ratio (Kapetanov et al. 2010; Bradbury 2001). Although antibiotics are commonly used to reduce the effects of Mycoplasmas infections, they are ineffective at clearing $M$. gallisepticum lesions (Ley and Yoder 1997; Elazab et al. 2021). Mycoplasmas are resistant to $\beta$-lactams antibiotics

Cite This Article as: Bastamy M, Raheel I, Ellakany H and Orabi A, 2022. Study of minimum inhibitory concentration against a local field isolates of Mycoplasma gallisepticum and Mycoplasma synoviae from Egyptian broiler and layer chicken flocks. International Journal of Veterinary Science 11(1): 98-103. https://doi.org/10.47278/journal.ijvs/2021.081 
because of the absence of cell-wall structure, so the drug of choice for the therapy for mycoplasmosis were fluroquinolones, tetracyclines, macrolides and pleuromutilin which induce DNA fragmentation or inhibition of protein synthesis (Behbahan et al. 2008). Macrolide antibiotics are the most common antimycoplasma agents used in Egyptian flocks that are classified as macrocyclic lactones with 12-20 carbon atoms in the lactone ring at which several combinations of de-oxy sugars can be attached by glycosidic linkages (Watteyn et al. 2013). Acetyl-iso-valeryl-tyrosine tartrate (Tylvalosin /Tylvamyco ${ }^{\circledR}$ ) is a member of the macrolide group commonly used in poultry farms for the treatment of respiratory infections specially the treatment of mycoplasmosis at the recommended dose $25 \mathrm{mg} \cdot \mathrm{kg}^{-1}$ for 3 days (Forrester et al. 2011; Bastamy et al. 2020). Mycoplasmas have mutation rates higher than conventional bacteria which means that they can rapidly develop resistance to other drugs including the tylosin and oxytetracyclines as has been reported in Europe (Ahling et al. 2000). The massive use of anti-mycoplasma agents led to the emergence of resistant Mycoplasma gallisepticum and Mycoplasma synoviae strains (Gautier-Bouchardon et al. 2002). However, the carrier state of infected poultry is not eliminated by drugs application but only suppresses the excretion in respiratory secretions and eggs (Stipkovits 2000). Few reports on the minimum inhibitory concentration values for avian mycoplasmas are available in literature, despite in the last years, the need of updated data become urgent (Lysnyansky et al. 2013), As knowing the antibiotic susceptibility of the circulating strains is very important for better managing the drug therapy, so the present investigation aimed to focus on the current antimicrobial susceptibility profiles of local Mycoplasma gallisepticum and Mycoplasma synoviae recovered from broiler and layer flocks in Egypt.

\section{MATERIALS AND METHODS}

\section{Mycoplasma Isolates}

The examined isolates used in this study were $M$. gallisepticum (MG) recovered from broiler chickens suffered from respiratory complains. MG isolate accessed on GenBank and coded as; BankIt2433660 MGEGY/ORABI/Raheel/2020 MW679029, M. synoviae (MS) isolate recovered from arthritis of layer chickens and accessed on GenBank coded as; BankIt2433662 MSEGY/ORABI/Raheel/2020 MW679030.

\section{In Vitro Cultivation of Mycoplasma Isolates}

The examined $M$. gallisepticum and $M$. synoviae isolates were re-cultured and subcultured on Frey's broth, and adjusted finally to $10^{5} \mathrm{cfu} / \mathrm{mL}$ followed by inoculation onto an agar plate of Avian Mycoplasma Agar for regular microscopic examination (Behbahan et al. 2008).

\section{In vitro Preparation of Antimicrobials}

Antimicrobial agents used during this study originated from Sigma-Aldrich, Germany as the following: fluoroquinolones: Difloxacin (DIF) and Enrofloxacin (ENR); aminoglycoside: Spectinomycin (SPC) and Dihydro-streptomycin (DHS); lincosamides: Lincomycin (LCM); the tetracyclines: doxycycline (DOX), chlortetracycline (CTC) and oxytetracycline (OTC); the Macrolides: Tylvalosin (TVN) $\left(\right.$ Tylvamyco $\left.^{\circledR}\right)$ was obtained as $62.5 \%$ water-soluble white granules (ATCO distributed by $\mathrm{MN}$ trade company, Egypt) at which Each gram powder contains $625 \mathrm{mg}$ of TVN as TVN tartrate., Tilmicosin (TIL), Tylosin (TYL), Spiramycin (SPM) and Erythromycin (ERY); and pleuromutilin: Tiamulin (TIA).The antibiotics were prepared according to the recommendations of producer and dilutions of the antibiotics were freshly prepared for each agent from the aliquots stored at $-70^{\circ} \mathrm{C}$ and two fold serial dilutions were prepared for detection of MICs values (Hannan 2000).

\section{Determination of Minimum Inhibitory Concentration of MG and MS}

According to (Hannan 2000; CLSI 2011), the clinical isolates were tested on each 96 well microtiter plates by using the micro broth dilution methods at which $10^{4}$ $10^{5} \mathrm{cfu} / \mathrm{mL}$ of the strains were performed in mycoplasma broth medium with controlled $\mathrm{pH}$ value (broth medium adjusted to $\mathrm{pH}$ 6.8). MIC values were determined from the lowest concentrations of the antibiotics where no $\mathrm{pH}$ and color change of the broth was detected after one week of incubation, while $\mathrm{MIC}_{50}$ and $\mathrm{MIC}_{90}$ values were defined as the lowest conc. that inhibited the growth of $50 \%$ or $90 \%$ of the strains, respectively.

\section{Statistical Analysis}

GLM procedure used for Data analysis and the means were compared following the Tukey's method of SAS (SAS Institute 2008). which depend mainly on calculation of the averages and the standard deviation between the recorded data.

\section{RESULTS}

The results in Table 1 and Fig. 1 and 2 showed that the MICs ( $\mathrm{MIC}, \mathrm{MIC}_{50}$ and $\left.\mathrm{MIC}_{90}\right)(\mu \mathrm{g} / \mathrm{mlL}$ values against examined $M$. gallisepticum (MG) MW679029 and $M$. synoviae (MS) MW679030 were as the following: fluoroquinolones as enrofloxacin at a dilution range 0.1 $2 \mu \mathrm{g} / \mathrm{mL}$, the MIC, MIC50, and MIC90 were 0.2, 0.6 and $1.32 \mu \mathrm{g} / \mathrm{mL}$ against $M$. gallisepticum and $0.4,0.7$ and $1.5 \mu \mathrm{g} / \mathrm{mL}$ against $M$. synoviae, while difloxacin at the same dilution range the MICs value were $0.2,0.7$ and $1.3 \mu \mathrm{g} / \mathrm{mL}$ against $\mathrm{MG}$ and $0.4,0.7$ and $1.6 \mu \mathrm{g} / \mathrm{mL}$ against $\mathrm{MS}$. Aminoglycosides as spectinomycin at dilution range 0.5 $16 \mu \mathrm{g} / \mathrm{mL}$ showed MICs values 3.6, 5.4 and 8.6 against MG and more than $16 \mu \mathrm{g} / \mathrm{mL}$ against $\mathrm{MS}$, while dihydrostreptomycin values were more than $16 \mu \mathrm{g} / \mathrm{mL}$ against MG and MS, in the other hand lincosamides as lincomycin at the same dilution range slowed MICs values of 4.6,12.9 and more than $16 \mu \mathrm{g} / \mathrm{mL}$ against $\mathrm{MG}$, while $M$. synoviae MICs values were more than $16 \mu \mathrm{g} / \mathrm{mL}$. Tetracyclines as oxytetracyclines and chlortetracycline at dilution range $0.5-8 \mu \mathrm{g} / \mathrm{mL}$ showed MICs values ranged from $0.5,0.7$ and $1.9 \mu \mathrm{g} / \mathrm{mL}$ against $\mathrm{MG}$ and $0.5,0.7$ and $2 \mu \mathrm{g} / \mathrm{mL}$ against $\mathrm{MS}$, while doxycycline at dilution range $0.1-2 \mu \mathrm{g} / \mathrm{mL}$ showed 0.3,0.6 and 1.4 against $\mathrm{MG}$ and 0.2, 0.6 and $1.6 \mu \mathrm{g} / \mathrm{mL}$ against MS. Macrolides as tylvalosin at dilution range $0.01-2 \mu \mathrm{g} / \mathrm{mL}$ showed the lowest values among the studied antibiotics as MICs value were 0.001 , 0.005 and $0.008 \mu \mathrm{g} / \mathrm{mL}$ against $\mathrm{MG}$ and $0.02,0.25$ and 
Int J Vet Sci, 2022, 11(1): 98-103.

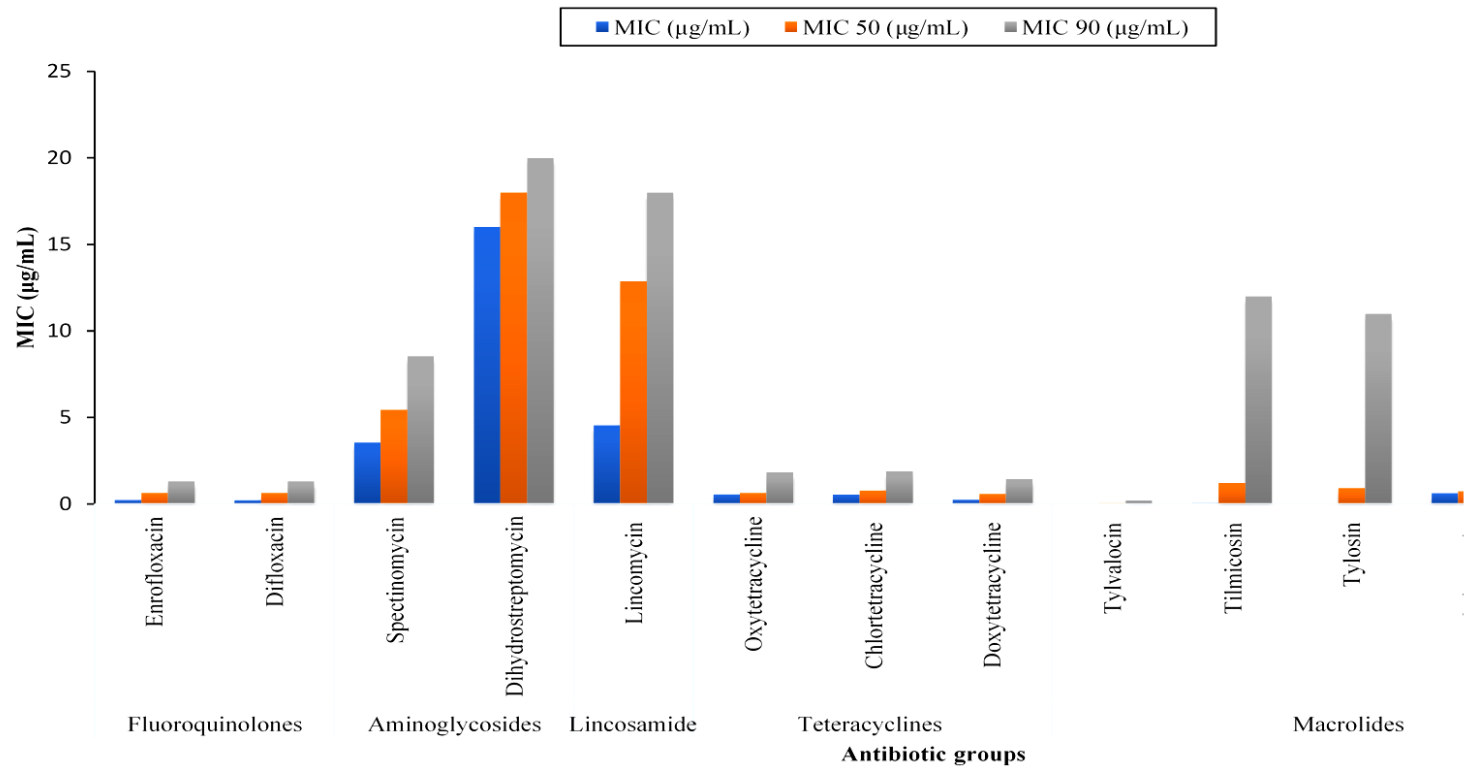

Fig 1: MICs value of the common anti-mycoplasma drugs against local Egyptian M. gallisepticum

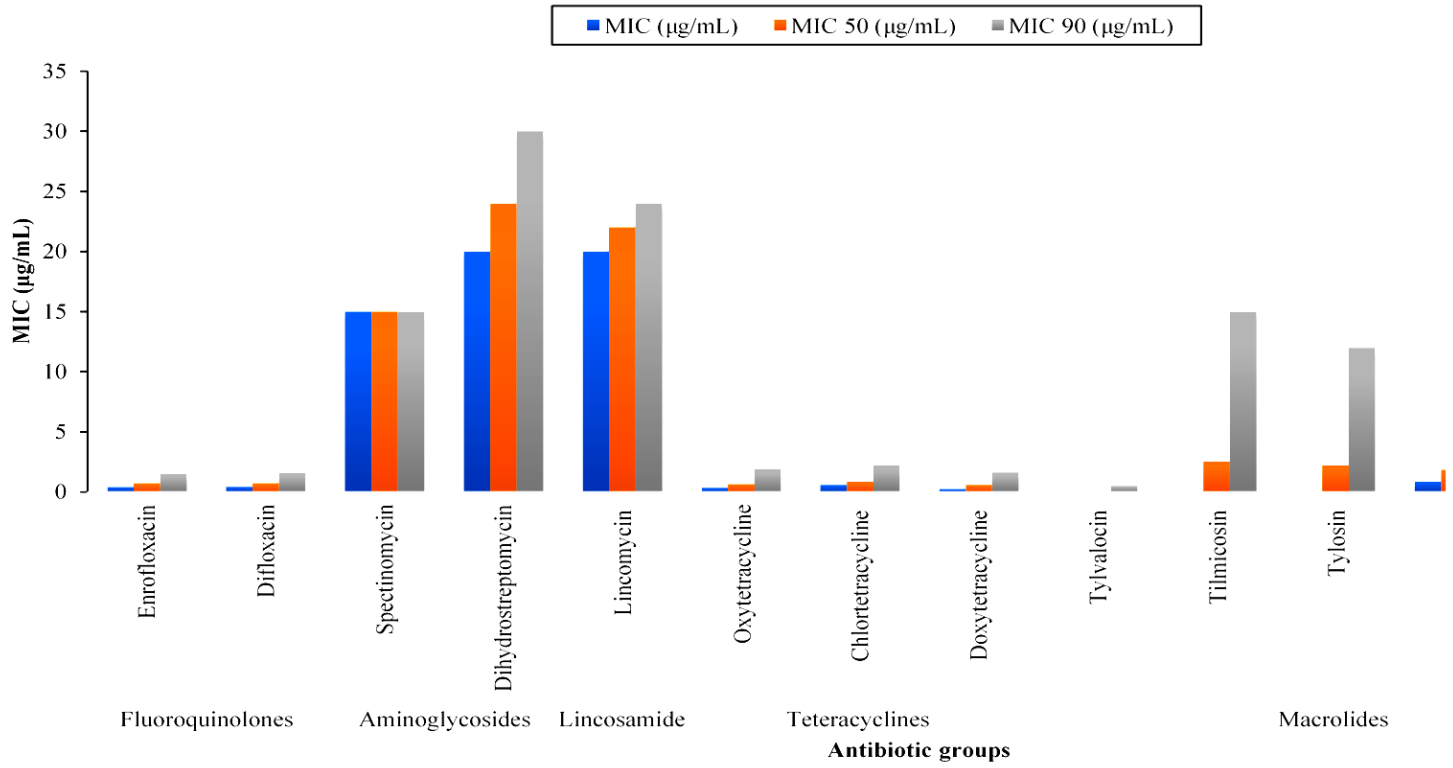

Fig. 2: MICs value of the common anti-mycoplasma drugs against local Egyptian M. synoviae

Table 1: MICs values of the common anti-mycoplasma drugs against local Egyptian M. gallisepticum and M. synoviae

\begin{tabular}{|c|c|c|c|c|c|c|c|c|}
\hline \multirow{3}{*}{$\begin{array}{l}\text { Antibiotic } \\
\text { Groups }\end{array}$} & \multirow[t]{3}{*}{ Antibiotic members } & \multirow{3}{*}{$\begin{array}{l}\text { Dilution } \\
\text { range } \\
(\mu \mathrm{g} / \mathrm{mL})\end{array}$} & \multicolumn{6}{|c|}{ Minimum inhibitory concentration values $(\mu \mathrm{g} / \mathrm{mL})$} \\
\hline & & & \multicolumn{3}{|c|}{ M. gallisepticum } & \multicolumn{3}{|c|}{ M. synoviae } \\
\hline & & & MIC & MIC 50 & MIC 90 & MIC & MIC 50 & MIC 90 \\
\hline \multirow[t]{2}{*}{ Fluoroquinolones } & Enrofloxacin & $0.1-2$ & 0.23 & 0.64 & 1.32 & 0.42 & 0.72 & 1.52 \\
\hline & Difloxacin & $0.1-2$ & 0.22 & 0.65 & 1.32 & 0.44 & 0.73 & 1.58 \\
\hline \multirow[t]{2}{*}{ Aminoglycosides } & Spectinomycin & $0.5-16$ & 3.55 & 5.44 & 8.55 & $>16$ & $>16$ & $>16$ \\
\hline & Dihydrostreptomycin & $0.5-16$ & 16 & $>16$ & $>16$ & $>16$ & $>16$ & $>16$ \\
\hline Lincosamide & Lincomycin & $0.5-16$ & 4.55 & 12.88 & $>16$ & $>16$ & $>16$ & $>16$ \\
\hline \multirow[t]{3}{*}{ Teteracyclines } & Oxytetracycline & $0.5-8$ & 0.56 & 0.65 & 1.84 & 0.35 & 0.65 & 1.88 \\
\hline & Chlortetracycline & $0.5-8$ & 0.55 & 0.78 & 1.88 & 0.58 & 0.85 & 2.21 \\
\hline & Doxycycline & $0.1-2$ & 0.25 & 0.58 & 1.44 & 0.23 & 0.58 & 1.62 \\
\hline \multirow[t]{5}{*}{ Macrolides } & Tylvalosin & $0.001-2$ & 0.001 & 0.005 & 0.008 & 0.02 & 0.25 & 0.5 \\
\hline & Tilmicosin & $0.01-16$ & 0.06 & 1.22 & 12 & 0.08 & 2.52 & 15 \\
\hline & Tylosin & $0.01-16$ & 0.06 & 0.92 & 11 & 0.08 & 2.2 & 12 \\
\hline & Spiramycin & $0.5-8$ & 0.62 & 0.75 & 4.24 & 0.84 & 1.85 & 4.52 \\
\hline & Erythromycin & $0.5-8$ & 8 & $>8$ & $>8$ & $>8$ & $>8$ & $>8$ \\
\hline Pleuromutilins & Tiamulin & $0.01-2$ & 0.07 & 0.55 & 1.42 & 0.08 & 0.65 & 1.78 \\
\hline
\end{tabular}


$0.5 \mu \mathrm{g} / \mathrm{mL}$ against $\mathrm{MS}$, while tilmicosin and tyrosine at dilution range $0.1-16 \mu \mathrm{g} / \mathrm{mL}$ their values were $0.06,1.2,12$ and $0.06,0.9,11 \mu \mathrm{g} / \mathrm{mL}$ respectively against $\mathrm{MG}$ and $0.08,2.5,15$ and $0.08,2.2,12 \mu \mathrm{g} / \mathrm{mL}$ against MS. In the other hand spiramycin at dilution range $0.5-8 \mu \mathrm{g} / \mathrm{mL}$ showed MICs value $0.6,0.8$ and $4.4 \mu \mathrm{g} / \mathrm{mL}$ against $\mathrm{MG}$ and $0.8,1.9$ and $4.5 \mu \mathrm{g} / \mathrm{mL}$ against MS, while erythromycin at dilution range $0.5-8 \mu \mathrm{g} / \mathrm{mL}$ showed MICs value more than $8 \mu \mathrm{g} / \mathrm{mL}$ against $\mathrm{MG}$ and MS. Pleuromutilin as timulin at dilution range $0.01-2 \mu \mathrm{g} / \mathrm{mL}$ showed MICs value $0.07,0.6$ and $1.4 \mu \mathrm{g} / \mathrm{mL}$ against $\mathrm{MG}$ and $0.08,0.7$ and 1.8 against MS.

\section{DISCUSSION}

Mycoplasma are found on mucosal surfaces of the respiratory tract of the birds so it needs a host to be live and persist for short time in the external environment (Kapetanov et al. 2010). M. gallisepticum is the causative agent for chronic respiratory disease in broiler chickens, the disease not only causes losses in weight gain, disturbance in feed conversion efficiency, elevation in mortality rate and severe condemnations in the slaughterhouses, but also transmitted horizontally and vertically and the flock remain suffering from subclinical infections (Gharaibeh and Al Roussan 2008; Markey et al. 2013). There are many predisposing factors that affect mycoplasmas occurrence among broiler and layer chicken flocks as the immune condition of birds, litter quality, overcrowdings, adverse climate, fomites and workers have a role in transmission and infections (Nneoma Okwara 2016). Low pathogenic avian influenza mixed infection with $\mathrm{MG}$ in chickens has been recorded (Stipkovits et al. 2012; Sid et al. 2016), also infection with IBV, E. coli or other pathogens make disease more serious (Matilda et al. 2018; Nneoma Okwara 2016). Mycoplasmas pathogenesis shows that it is a facultative intracellular organisms, which can adhere to host target cells, stimulate apoptosis (Nascimento 2000). $M$. gallisepticum prevalence poultry flocks in developing countries poultry flocks as Malaysia was $43 \%$ layer and $64 \%$ broiler (Ching et al. 2016), 45.1, 53.4 and $29.5 \%$ in Bangladesh and Pakistan and Ghana, respectively (Hossain et al. 2010; Hussain et al. 2018; Matilda et al. 2018; Peebles and Branton 2012), while in Belgium the incidence of $\mathrm{MG}$ Layers flocks was 0.9 and $2.7 \%$ in broilers chickens (Michiels et al. 2016). Mostly subclinical M. synoviae infection in wild birds which characterized by respiratory and arthritis signs resulting in pneumonia, synovitis and bursitis mainly with egg deformity as thinning, breaks and cracks (Ferguson and Noormohammadi 2013; Feberwee et al. 2009). In the current study the local isolate $M$. gallisepticum recovered from broiler chickens suffered from respiratory signs and accessed on GenBank coded MW679029, while $M$. synoviae isolate was recovered from arthritis in layer chickens and accessed on GenBank coded MW679030. The two isolates were examined against most common anti-mycoplasmas drugs as fluoroquinolones: Difloxacin and Enrofloxacin; aminoglycoside: Spectinomycin and Dihydro-streptomycin; lincosamides: Lincomycin; the tetracyclines: doxycycline, chlortetracycline and oxytetracycline; the Macrolides: Tylvalosin, Tilmicosin, Tylosin, Spiramycin and Erythromycin; pleuromutilins: Tiamulin. Treatment of mycoplasma-infected flocks with antibiotics decreases the clinical signs and the risk of transovarian transmission (Ortiz et al. 1995; Stipkovits and Kempf 1996). Mycoplasmas are resistant to antibiotics that act on cell wall peptidoglycan, such as penicillin, but are sensitive to tetracyclines, macrolides and quinolones as these drugs accumulate in high concentrations in the mucosal membranes of the respiratory and genital tracts (Nascimento et al. 1999; Stipkovits and Kempf 1996; Hannan et al. 1997). The present study aimed at updating the MICs data of the local MG and MS isolates recovered from Egyptian flocks and the results in Table 1 and Fig . 1 and 2 showed that enrofloxacin and difloxacin at a the same dilution range, mainly have nearly MICs values against $\mathrm{MG}$ and $\mathrm{MS}$ as the following; $\mathrm{MIC}, \mathrm{MIC}_{50}$, and $\mathrm{MIC}_{90}$ were $0.2,0.6$ and $1.32 \mu \mathrm{g} / \mathrm{mL}$ against $M$. gallisepticum and $0.4,0.7$ and $1.5 \mu \mathrm{g} / \mathrm{mL}$ against $M$. synoviae, while only spectinomycin from aminoglycosides group showed valuable results dilution range $0.5-16 \mu \mathrm{g} / \mathrm{mL}$ which were MICs values 3.6,5.4 and 8.6 against MG and more than $16 \mu \mathrm{g} / \mathrm{mL}$ against MS, in the other hand lincomycin at the same dilution rate slowed MICs values 4.6, 12.9 and more than $16 \mu \mathrm{g} / \mathrm{mL}$ against MG, while $M$. synoviae MICs values were more than $16 \mu \mathrm{g} / \mathrm{mL}$. Doxycycline act as the potent agent against Mycoplasmas among tetracyclines group as at dilution range $0.1-2 \mu \mathrm{g} / \mathrm{mL}$ showed $0.3,0.6$ and 1.4 against $\mathrm{MG}$ and $0.2,0.6$ and $1.6 \mu \mathrm{g} / \mathrm{mL}$ against $\mathrm{MS}$, while oxytetracyclines and chlortetracycline at dilution range $0.5-8 \mu \mathrm{g} / \mathrm{mL}$ showed MICs values ranged from $0.5,0.7$ and $1.9 \mu \mathrm{g} / \mathrm{mL}$ against $\mathrm{MG}$ and $0.5,0.7$ and $2 \mu \mathrm{g} / \mathrm{mL}$ against $\mathrm{MS}$. The truth is not denied that the antibiotic susceptibility assay is predicted in vivo success or failure of therapy through measuring the growth response of an isolated organism to specific agents (Bradbury and Morrow 2008). In the present study the Macrolides as tylvalosin at dilution range $0.001-2 \mu \mathrm{g} / \mathrm{mL}$ showed the lowest values among the studied antibiotics as MICs value were 0.001,0.005 and $0.008 \mu \mathrm{g} / \mathrm{mL}$ against $\mathrm{MG}$ and $0.02,0.25$ and $0.5 \mu \mathrm{g} / \mathrm{mL}$ against MS, while tilmicosin and tylosin at the same dilution range, their values were $0.06,1.2,12$ and $0.06,0.9$, $11 \mu \mathrm{g} / \mathrm{mL}$ respectively against $\mathrm{MG}$ and $0.08,2.5,15$ and $0.08,2.2,12 \mu \mathrm{g} / \mathrm{mL}$ against MS. In the other hand spiramycin at dilution range $0.5-16 \mu \mathrm{g} / \mathrm{mL}$ showed MICs value $0.6,0.8$ and $4.4 \mu \mathrm{g} / \mathrm{mL}$ against $\mathrm{MG}$ and $0.8,1.9$ and $4.5 \mu \mathrm{g} / \mathrm{mL}$ against $\mathrm{MS}$, while erythromycin at dilution range $0.5-8 \mu \mathrm{g} / \mathrm{mL}$ showed MICs value more than $8 \mu \mathrm{g} / \mathrm{mL}$ against MG and MS. Finally, pleuromutilin as timulin at dilution range $0.01-8 \mu \mathrm{g} / \mathrm{mL}$ showed MICs value $0.07,0.6$ and $1.4 \mu \mathrm{g} / \mathrm{mL}$ against MG and $0.08,0.7$ and 1.8 against MS. Unfortunately, the minimum inhibitory concentrations of antimicrobials in vitro studies shown resistance to some macrolides and enrofloxacin, while no resistance to tiamulin or tylvalosin could be evidenced in M. gallisepticum or M. synoviae, but mutants Mycoplasma spp. that became resistant to tylosin were also resistant to erythromycin, whereas mutants resistant to erythromycin were not always resistant to tylosin (Gautier-Bouchardon et al. 2002). A study in Israel collected during 2005-2006 indicated decrease in susceptibility against enrofloxacin and difloxacin compared with archived strains (19972003) (Gerchman et al. 2008), this is agreeing with a study from Jordan at which compared MICs of Mycoplasma isolates recovered from 2004 to 2005 vs. strains isolated during 2007-2008 confirmed a significant increase in MIC 
values (Gharaibeh and Al-Rashdan 2011). A new macrolides agent as tylvalosin is the useful economic drug in the treatment and control of Mycoplasma spp. infection and tiamulin from pleuromutilin group. However, tiamulin medication is contraindicated in flocks with ionophore antimicrobials, since it may lead to toxicity (Horrox 1980). In conclusion studying MICs values variation will be fundamental in order to create a significant database that would direct veterinarians in selecting the proper drug for treating these impactful Mycoplasma infections. The current study proved that till now the tylvalosin macrolides is the most efficient drugs in controlling MG and MS as it has the lowest MICs values.

\section{Author's Contribution}

All authors contributed equally to study the design methodology, interpretation of results, and writing of the manuscript.

\section{Acknowledgment}

We gratefully thank Dr. Moatasem Nowara the Chairman of MN Trade Veterinary Pharmaceutical Company for Antibiotic Supply.

\section{REFERENCES}

Ahling RD, Baker ES, Nicholas RAJ, Peek ML and Simon AJ, 2000. Comparison of in vitro activity of danofloxacin, florfenicol, oxytetracycline, spectinomycin and tilmicosin against recent field isolates of Mycoplasma bovis. Veterinary Record 146: 745-747. https://doi.org/10.1136/vr.146.26.745

Bastamy M, Raheel I, Ellakany H and Orabi A, 2020. Treasing study on tylvamyco® as a novel immunomodulatory medication for broiler chickens. International Journal of Veterinary Science 9: 523-527. https://doi.org/10.37422/ IJVS/20.074

Behbahan NGG, Asaki K, Afsharifar AR and Pourbakhsh SA, 2008. Susceptibilities of Mycoplasma gallisepticum and Mycoplasma synoviae isolates to antimicrobial agents in vitro. International Journal of Poultry Science 7: 1058-1064. https://doi.org/10.3923/ijps.2008.1058.1064

Bosila MA, Mekky HM, Fedawy HS, Elbayomi KM and Amer MM, 2021. Histopathological lesion of arthritis in Mycoplasma synoviae naturally infected breeder chicken in Egypt. International Journal of Veterinary Science 10: 7274. https://doi.org/10.47278/journal.ijvs/2020.006

Bradbury JM and Morrow C, 2008. Chapter 20-Avian mycoplasmas. In: Poultry Diseases. $6^{\text {th }}$ Ed, Pattison M, McMullin P, Bradbury JM (eds), Edinburgh/New York, USA, pp: 220-233.

Bradbury JM, 2001. Avian mycoplasmosis, In: Poultry Diseases. Jordan, $5^{\text {th }}$ Ed. F. et al. (eds.). W. B. Saunders Company, Iowa pp: 178-193.

Ching GT, Mahadevan J, Aini I, Sheikh O, Abdul R, Abdul RM and Nadzri S, 2016. Prevalence of Mycoplasma gallisepticum in commercial chickens and free flying birds. Journal of Agriculture and Veterinary Science 9: 89-95. https://doi.org/10.9790/2380-0912018995

CLSI, 2011. Methods for antimicrobial susceptibility testing for human mycoplasmas: approved guideline. Clinical and Laboratory Standards Institute document. M43-A Vol. 31 No. 19. Available from: https://clsi.org/standards/products/ microbiology/documents $/ \mathrm{m} 43 /$

Dufour-Gesbert F, Dheilly A, Marois C and Kempf I, 2006. Epidemiological study on Mycoplasma synoviae infection in layers, Veterinary Microbiology 114: 148-154. https://doi.org/10.1016/j.vetmic.2005.10.040
Elazab ST, Elshater NS, Hashem YH and Abdelaziz AS, 2021. Pharmacokinetics of tildipirosin in healthy and Mycoplasma gallisepticum infected chickens. International Journal of Veterinary Science 10: 119-123. https://doi.org/10.47278/ journal.ijvs/2021.047

Feberwee A, de Wit JJ and Landman WJ, 2009. Induction of eggshell apex abnormalities by Mycoplasma synoviae: field and experimental studies. Avian Pathology 38: 77-85. https://doi.org/10.1080/03079450802662772

Ferguson NN and Noormohammadi HA, 2013. Mycoplasma synoviae infection. In: Diseases of Poultry, $13^{\text {th }} \mathrm{Ed}$, Swayne DE. Editor. Wiley-Blackwell, Ames, Iowa pp: 900-906.

Forrester CA, Bradbury JM, Dare CM, Domangue RJ, Windsor H, Tasker JB and Mockett AA, 2011. Mycoplasma gallisepticum in pheasants and the efficacy of tylvalosin to treat the disease. Avian Pathology 40: 581-586. https://doi.org/10.1080/03079457.2011.618822

Gautier-Bouchardon AV, Reinhardt AK, Kobisch M and Kempf I, 2002. In vitro development of resistance to enrofloxacin, tylosin, tiamulin and oxytetracycline in Mycoplasma gallisepticum, Mycoplasma iowae and Mycoplasma synoviae. Veterinary Microbiology 88: 47-58. https://doi.org/10.1016/s0378-1135(02)00087-1

Gerchman I, Lysnyansky I, Perk S and Levisohn S, 2008. In vitro susceptibilities to fluoroquinolones in current and archived Mycoplasma gallisepticum and Mycoplasma synoviae isolates from meat-type turkeys. Veterinary Microbiology 131: 266-276. https://doi.org/10.1016/j.vetmic.2008.04.006

Gharaibeh S and Al-Rashdan M, 2011. Change in antimicrobial susceptibility of Mycoplasma gallisepticum field isolates. Veterinary Microbiology 150: 379-383. https://doi.org/ 10.1016/j.vetmic.2011.02.005

Gharaibeh S and Al Roussan D, 2008. The use of molecular techniques in isolation and characterization of Mycoplasma gallisepticum from commercial chickens in Jordan. International Journal of Poultry Science 7: 28-35. https://doi.org/10.3923/ijps.2008.28.35

Hannan PCT, Windsor GD, de Jong A, Schmeer N and Stegemann H, 1997. Comparative susceptibilities of various animal-pathogenic mycoplasmas to fluoroquinolones. Antimicrobial Agents Chemotherapy 41: 2037-2040.

Hannan PCT, 2000. Guidelines and recommendations for antimicrobial minimum inhibitory concentration (MIC) testing against veterinary mycoplasma species. Veterinary Research 31: 373-95. https://doi.org/10.1051/vetres2000100

Horrox NE, 1980. Monensin-tiamulin interaction risk to poultry. Vet Record 106: 278. https://doi.org/10.1136/vr.106.12.278

Hossain KMM, Hossain MT and Yamato I, 2010. Seroprevalence of Salmonella and Mycoplasma gallisepticum infection in chickens in Rajshahi and surrounding districts of Bangladesh. International Journal of Biology 2: 74-80. https://doi.org/10.5539/ijb.v2n2p74

Hussain A, Adnan Y, Mushtaq A and Rais MN, 2018. Prevalence of Mycoplasma gallisepticum in ross-308 broiler breeder through the contrast of serological assessments in Pakistan. Journal of Dairy, Veterinary and Animal Research 7: 00185. https://doi.org/10.15406/jdvar.2018.07.00185

Kapetanov M, Orlic D, Potkonjak D, Velhner M, Stojanov I, Milanov D and Stojanovic D, 2010. Mycoplasma in poultry flocks in the year 2009 compared to the year 2000 and significance of the control measures. Lucrari Stiintifice Medicina Veterinara 1: 249-253.

Ley DH and Yoder HW, 1997. Mycoplasma gallisepticum infection In: Disease of poultry, $10^{\text {th }}$ Ed. Calnek BW, Barnes HJ, Beard CW, McDougald LR, Saif YM. eds. Iowa state, University Press, Ames, Iowa, USA, pp: 194-207.

Lockaby B, Hoerr FJ, Lauerman LH and Kleven SH, 1998. Pathogenicity of Mycoplasma synoviae in broiler chickens, Veterinary Pathology 35: 178-190. https://doi.org/ $\underline{10.1177 / 030098589803500303}$ 
Lysnyansky I, Gerchman I, Mikula I, Gobbo F, Catania S and Levisohn S, 2013. Molecular characterization of acquired enrofloxacin resistance in Mycoplasma synoviae field isolates. Antimicrobial Agents Chemotherapy 57: 30723077. https://doi.org/10.1128/AAC.00203-13

Markey B, Leonard F, Archambault M, Cullinane A and Maguire D, 2013. The Mycoplasmas (class: Mollicutes). In: Markey B, Leonard F, Archambault M, Cullinane A, Maguire D, editors. Clinical Veterinary Microbiology. $2^{\text {nd }}$ Ed. Mosby Elsevier pp: 423-431.

Matilda AA, Kwasi OD, Toah-Akonor P and Sellers HS, 2018. Widespread exposure to infectious bronchitis virus and Mycoplasma gallisepticum in chickens in the Ga-East district of Accra, Ghana. Cogent Food Agriculture. 4: 1439260. https://doi.org/10.1080/23311932.2018.1439260

Michiels T, Sarah W, Mia V, Christian Q, Lieze R, Luc L, Martelc A and Butayea P, 2016. Prevalence of Mycoplasma gallisepticum and Mycoplasma synoviae in commercial poultry, racing pigeons and wild birds in Belgium. Avian Pathology 45: 244-252. https://doi.org/10.1080/03079457. 2016.1145354

Nascimento ER, Nascimento MGF, Rodrigues OP, Mendonça GA, Lignon GB, Dias SAC and Ito JY, 1999. Avaliação de antimicrobianos no tratamento da doença respiratória crônica por Mycoplasma gallisepticum e Escherichia coli em frangos de corte. Brazilian Journal of Poultry Science 1999a; Supl: pp: 72.

Nascimento ER, 2000. Mycoplasmoses. In: Doenças das aves. Macari M, Berchieri Jr. A, editores. Campinas: FACTA; pp: 217-24.

Nneoma Okwara, 2016. Avian Mycoplasmosis: A Review. Journal Agriculture and Veterinary Science 9: 06-10.

OIE, 2007. Avian mycoplasmosis (Mycoplasma gallisepticum). http://www.oie.int/eng/norms/mmanual/A_00104.htm

OIE, 2008. Manual of diagnostic tests and vaccines for terrestrial animals. Chapter 2.3.5: Avian mycoplasmosis (Mycoplasma gallisepticum, M. synoviae), pp: 482-496.

Ortiz A, Froyman R and Kleven SH, 1995. Evaluation of enrofloxacin against egg transmission of Mycoplasma gallisepticum. Avian Diseases 39: 830-6.
Peebles ED and Branton SL, 2012. Mycoplasma gallisepticum in the commercial egg-laying hen: A historical perspective considering the effects of pathogen strain, age of the bird at inoculation, and diet on performance and physiology. The Journal of Applied Poultry Research 21: 897-914. https://doi.org/10.3382/japr.2012-00555

Ramirez Ana S, Naylor C J, Hammond P and Bradbury JM, 2006. Development and evaluation of a diagnostic PCR for Mycoplasma synoviae using primers located in the intergenic spacer region and the $23 \mathrm{~S}$ rRNA gene. Veterinary Microbiology 118: 76-82. https://doi.org/10.1016/j. vetmic. 2006.06.021

Sid H, Hartmann S, Petersen H, Ryll M and Rautenschlein S, 2016. Mycoplasma gallisepticum modifies the pathogenesis of influenza A virus in the avian tracheal epithelium. International Journal of Medical Microbiology 306: 174-86. https://doi.org/10.1016/j.ijmm.2016.04.001

SAS Institute, 2008. SAS User's Guide: Statistics

Stipkovits L and Kempf I, 1996. Mycoplasmoses in poultry. Revue scientifique et technique, office international Des Epizooties 15: 1495-525. https://doi.org/10.20506/rst. 15.4. $\underline{986}$

Stipkovits LT, 2000. Current questions of the control of Mycoplasma synoviae infection. Magyar Allatorvosok Lapja 122: 165-167.

Stipkovits L, Egyed L, Palfi V, Beres A, Pitlik E, Somogyi M, Szathmary S and Denes B, 2012. Effect of low-pathogenicity influenza virus $\mathrm{H} 3 \mathrm{~N} 8$ infection on Mycoplasma gallisepticum infection of chickens. Avian Pathology 41: 517. https://doi.org/10.1080/03079457.2011.635635

Valks M and Burch DG, 2002. Comparative Activity and Resistance Development of Tiamulin and Other Antimicrobials against Avian Mycoplasma, Presentation at the World Veterinary Poultry Association, Cairo, Egypt pp: 200.

Watteyn A, Plessers E, Wyns H, De Baere S, De Backer P and Croubels S, 2013. Pharmacokinetics of gamithromycin after intravenous and subcutaneous administration in broiler chickens. Poultry Science 92: 1516-1522. https://doi.org/ 10.3382/ps.2012-02932 